Journal of Case Reports 2018;8(2):109-111

\title{
High but not that High: Pulmonary Edema at Intermediate Altitude
}

\author{
Shreya Das Adhikari, Dara Singh, Kartik Syal, Anjna Badhan \\ Department of Anaesthesiology, Indira Gandhi Medical College, Shimla, Himachal Pradesh, India.
}

\section{Corresponding Author: \\ Dr. Dara Singh \\ Email: dara_negi556@hotmail.com}

This is an Open Access article distributed under the terms of the Creative Commons Attribution License (creativecommons.org/ licenses/by/3.0).

Received : February 4, 2018

Accepted : March 22, 2018

Published : April 30, 2018

\begin{abstract}
Background: Pulmonary edema is a life-threatening condition which results from a persistent imbalance between the forces that drive water into the air space in the alveoli and the physiologic mechanisms that remove it. This is generally observed with rapid ascent to altitudes greater than $2500 \mathrm{~m}$ in absence of acclimatization in otherwise healthy individuals. Case Report: A 35 year old female tourist hailing from Hyderabad developed severe breathlessness, dizziness and chest discomfort on the second day of her trip to Shimla, Himachal Pradesh. This was associated with drop in saturation and bilateral coarse crepitations in all lung fields. She was initially managed with $\mathrm{O}_{2}$ inhalation, bilevel positive airway pressure and furosemide. $\mathrm{SpO}_{2}$ increased to $84 \%$ gradually. Following her chest $\mathrm{X}$ ray which showed bilateral lung infiltrates, she was started on morphine, furosemide, dexamethasone and referred to a tertiary care hospital in the plains. On follow up at the hospital she was told to have improved drastically in terms of saturation, hemodynamics and chest X-ray picture. Conclusion: Even though high altitude sickness manifests at altitudes higher than $2500 \mathrm{~m}$, that too on rapid ascent, cases have been reported at lower heights too. And the definitive treatment is transferring the patients to lowlands.
\end{abstract}

Keywords: Altitude Sickness, Dizziness, Hypoxia, Oxygen, Pulmonary Edema.

\section{Introduction}

Pulmonary edema is a life-threatening condition which results from a persistent imbalance between the forces that drive water into the air space in the alveoli and the physiologic mechanisms that remove it. Rapid ascent to altitudes greater than $2500 \mathrm{~m}$ in healthy individuals may lead to acute mountain sickness (AMS), high-altitude pulmonary edema (HAPE) or high altitude cerebral edema (HACE).

\section{Case Report}

A 35 years old female who was a resident of Hyderabad (height - $505 \mathrm{~m}$ ) was admitted in casualty with shortness of breath after one day stay at Shimla (height - $2276 \mathrm{~m}$ ). Shortness of breath was insidious onset, gradually progressive to present even at rest and increased on lying down. This was associated with headache, dizziness, intermittent darkness in front of eyes and chest tightness. There was no history of paroxysmal nocturnal dyspnea, pedal edema, cough, sputum production, nausea, vomiting, fever or decreased urine output. She had upper respiratory tract infection before travel and was on $25 \mu \mathrm{g}$ of thyroxine per day for hypothyroidism since last five years. On examination patient was cyanosed with blood pressure $160 / 100 \mathrm{mmHg}$; heart rate: 130/min; respiratory rate: $44 / \mathrm{min} ; \mathrm{SpO}_{2}: 48 \%$ at room air; $65 \%$ on high flow oxygen. She was overweight with bilateral coarse crepitations and wheeze all over the chest. She was afebrile with normal jugular venous pressure. Rest all examination was normal. Her laboratory reports showed leucocyte count 17,200/L; hemoglobin $14.2 \mathrm{gm} / \mathrm{dL} ; \mathrm{pH}: 7.377 ; \mathrm{paO}_{2}: 35.6 \mathrm{mmHg} ; \mathrm{pCO}_{2}$ : $26.9 \mathrm{mmHg} ; \mathrm{HCO}_{3}: 15.4 \mathrm{mmol} / \mathrm{L}$. Her chest X-ray view showed fluffy shadows in bilateral lung fields 
with no increased cardiac shadow whereas ECG was normal. Initially she was managed with $60 \% \mathrm{O}_{2}$ inhalation at rate of $6 \mathrm{~L} / \mathrm{min}$ in propped up position, injection furosemide $40 \mathrm{mg}$ intravenous repeated after 30 minutes, and urinary catheterization. Her $\mathrm{SpO}_{2}$ increased to $84 \%$; HR: 108/min; BP: $130 / 80 \mathrm{mmHg}$. She was shifted to intensive care unit immediately. She was put on bilevel positive airway pressure (bipap) with pressure support of $12 \mathrm{~cm} \mathrm{H}_{2} \mathrm{O}$ and ePAP of $6 \mathrm{~cm} \mathrm{H}_{2} \mathrm{O}$. She was administered injection morphine, furosemide (if $\mathrm{SBP}>100 \mathrm{mmHg}$ ), injection dexamethasone, tablet nifedipine. Arterial blood analysis after 6 hours: $\mathrm{pH}$ : 7.398; $\mathrm{paO}_{2}$ : $52.1 \mathrm{mmHg} ; \mathrm{pCO}_{2}$ : $38.3 \mathrm{mmHg} ; \mathrm{HCO}_{3}: 23.1 \mathrm{mmol} / \mathrm{L}$. Differential diagnosis for this case were complicated: lower respiratory tract infection, cardiogenic pulmonary edema, high altitude pulmonary edema (HAPE). The patient being overweight, the diagnosis of obstructive sleep apnoea was also considered. However, $\mathrm{paCO}_{2}$ levels were not less than normal, hence obstruction was ruled out. Since she had sudden onset illness with normal ECG and was afebrile, we decided to treat her in the lines of HAPE. Patient was referred to a hospital in the plains to facilitate descent to a lower altitude with $\mathrm{SpO}_{2}$ : 92\%; BP: 130/70 mmHg; HR: 102/min and chest with decreased crepitations bilaterally. The patient was doing well and maintaining saturation at the hospital and was discharged after being kept under observation for three days.

\section{Discussion}

High altitude pulmonary edema is a non-cardiogenic pulmonary edema occurring mainly in low-landers with rapid ascent above 2500-3000 m (rarely below $2500 \mathrm{~m}$ ) in absence of acclimatization. Usually occurs within 2-4 days of ascent [1,2], it rarely occurs after more than 4 or 5 days at the same altitude, most likely because of remodelling and adaptation [3]. The first modern English language report of HAPE, was published by Houston was in 1960 [4]. First case was reported in the Rocky mountains. Prevalence of this in Rocky Mountains

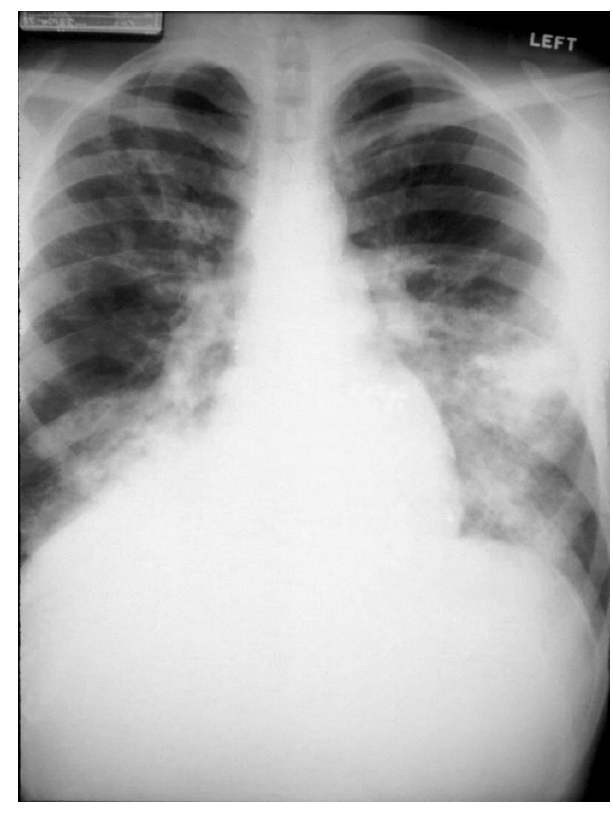

Fig.1: Bilateral fluffy infiltrates in chest $x$-ray.

is $0.01-0.1 \%$, Greater Alpines: $<0.2 \%$, Himalayas \& Alps: 4\%. A study conducted on 52 patients admitted to a hospital between 1992 and 2000 in the French Alps reported HAPE at moderate altitudes of between 1,400-2,400 m, though the incidence of HAPE at these altitudes is considered rare.

HAPE is commonly found to develop in association with AMS. Early symptoms include non-productive cough, dyspnea on exertion, reduced exercise performance. Later on there may be worsening of cough, breathlessness at rest or orthopnea. In advanced form there may be pink frothy sputum. There may be associated cyanosis, tachycardia, tachypnea, raised body temperature $<38.5^{\circ} \mathrm{C}$, rales (typically in middle zone). Chest $\mathrm{X}$-ray may show patchy opacities (often in right middle lobe). Ultrasound may show "Comet tail" pattern.

Prevention is best by slow ascent [6]. Other methods are acetazolamide [7] (125 mg 12 hourly starting as soon as possible, but not $>5$ days prior to ascent), nifedipine (an inhibitor of hypoxic pulmonary vasoconstriction) starting with the ascent and ending on the third or fourth day 
after arrival at the final altitude. Other less popular and effective methods are inhaled beta-2-receptor agonists (salmetrol), phosphodiesterase inhibitors and dexamethasone [8-10].

\section{Conclusion}

Even though HAPE is mostly observed in high altitudes, physicians working in intermediate altitudes should be aware of its occurrence when treating cases of breathlessness. Such cases are easily reversible and can save a good number of patients just by bringing them to low lands.

Contributors: SDA: manuscript writing, patient management; DS, KS: manuscript editing, patient management; AB: critical inputs into the manuscript. DS will act as guarantor. All authors approved the final version of this manuscript.

Funding: None; Competing interests: None stated.

\section{References}

1. Hackett PH, Roach RC. High altitude medicine. In: Auerbach PS, editor. Wilderness medicine. 5th ed. Philadelphia: Mosby Elsevier;2007.

2. Hultgren HN. High-altitude pulmonary edema: current concepts. Annu Rev Med. 1996;47:267-284.
3. West JB, Mathieu-Costello O. Structure, strength, failure, and remodeling of the pulmonary blood gas barrier [review]. Annu Rev Physiol. 1999;61:543.

4. Houston CS. Acute pulmonary edema of high altitude. $\mathrm{N}$ Engl J Med. 1960;263:478-480.

5. Gabry AL, Ledoux X, Mozziconacci M, Martin C. High-altitude pulmonary edema at moderate altitude $(<2,400 \mathrm{~m} ; 7,870$ feet): a series of 52 patients. Chest. 2003;123:49-53.

6. Bärtsch P. High altitude pulmonary edema. Med Sci Sports Exerc. 1999;31:S23-S27.

7. Swenson ER. Carbonic anhydrase inhibitors and ventilation: a complex interplay of stimulation and suppression. Eur Resp J. 1998;12:1242-1247.

8. Matthay MA, Flori HR, Conner ER, Ware LB. Alveolar epithelial fluid transport: basic mechanisms and clinical relevance. Proc Assoc Am Physicians. 1998;110:496505.

9. Richalet JP, Gratadour P, Robach P, Pham I, Déchaux M, Joncquiert-Latarjet A, et al. Sildenafil inhibits altitudeinduced hypoxemia and pulmonary hypertension. Am J Respir Crit Care Med. 2005;171:275-281.

10. Maggiorini M, Brunner-La Rocca HP, Peth S, Bernheim A, Kiencke S, Bloch KE, et al. Both Tadalafil and Dexamethasone may reduce the incidence of highaltitude pulmonary edema: A randomized trial. Ann Intern Med. 2006;145:497-506. 